\title{
Necessidade de avaliação das lesões dentais em casos de invalidez permanente por acidente
}

\author{
Need for assessment of dental injuries in cases of permanent disability \\ by accident
}

\author{
Fernanda Capurucho Horta Bouchardet \\ Sabrina Alves Teixeira* \\ Cristiane Miranda Carvalho** \\ Weliton Barbosa Santos ${ }^{* * *}$ \\ Duarte Nuno Pessoa Vieira ${ }^{* * * *}$ \\ Rhonan Ferreira da Silva ${ }^{* * * * *}$
}

\section{Resumo}

Objetivo: demonstrar a importância da avaliação das lesões dentais nas perícias de invalidez permanente por acidente, por meio de uma revisão de literatura e de análise de legislação específica. Revisão de literatura: o sistema estomatognático, quando equilibrado e controlado pelo sistema nervoso central, é responsável pelo funcionamento harmônico da face durante a respiração, mastigação, sucção, deglutição e fala. Nesse sistema, os dentes possuem papel fundamental nas funções mastigatória e fonética, e, apesar de serem considerados biologicamente como órgãos, a perda dental acidental não está amparada pela atual legislação securitária (Circular SUSEP 302/05 e a Resolução CNSP 117/04). Considerações finais: por falta de conhecimento específico nessa área, há uma incongruência entre a finalidade dos seguros de acidentes pessoais e a reparação de danos odontológicos, especialmente os dentais, de modo que se torna importante a divulgação dessas informações no âmbito odontológico e jurídico, para que as normativas legais possam ser alteradas e para que os beneficiários possam usufruir de forma justa e legal dos seus direitos.

Palavras-chave: Sistema estomatognático. Revisão da utilização de seguros. Odontologia legal.

\section{Introdução}

Dentre as inúmeras lesões ocorridas em centros de traumas urbanos, o traumatismo facial é um dos mais prevalentes. Por ser a parte mais exposta do corpo e a menos protegida, a face é a região mais relacionada a uma variedade de traumatismos ocorridos. Dentre os mecanismos que ocasionam o trauma facial, pode-se destacar os acidentes automobilísticos e a violência interpessoal ${ }^{1,2}$.

\footnotetext{
Mestra em Medicina Legal e Ciências Forenses - Universidade de Coimbra, Portugal. Coordenadora do curso de Especialização em Odontologia Legal PUCMG, Belo Horizonte, MG, Brasil.

Especialista em Odontologia Legal, Belo Horizonte, MG, Brasil.

*** Especialista em Medicina Legal, Belo Horizonte, MG, Brasil.

**** Instituto Nacional de Medicina Legal e Ciências Forenses (INMLCF), Faculdade de Medicina da Universidade de Coimbra e Faculdade de Ciências da Saúde Instituto Nacional de Medicina Legal e
da Universidade de Beira do Interior.

***** Doutor em Biologia Bucodental - Unicamp. Professor de Odontologia Legal UFG e UNIP, Goiânia, GO, Brasil.
} 
Tanto a face quanto o sistema estomatognático, sendo este último composto por estruturas estáticas/passivas (arcos dentais, maxila e mandíbula relacionados pela ATM, ossos do crânio e hioide) e por estruturas dinâmicas/ativas (estruturas passivas mobilizadas pelas estruturas neuromusculares) $)^{3}$, estão frequentemente sujeitos à ocorrência de lesões, em razão da facilidade com que essas regiões são atingidas por traumatismos em virtude da sua grande exposição $0^{4}$.

As lesões dentais podem ser consideradas parte das chamadas lesões corporais, isto é, toda e qualquer ofensa ocasionada à normalidade funcional do corpo ou organismo humano, seja do ponto de vista anatômico, fisiológico ou psíquico, e, assim sendo, encontram-se resguardadas no Código Penal brasileiro de 1940. Porém, devido ao desconhecimento da importância do sistema estomatognático no âmbito jurídico, que, quando equilibrado e controlado pelo sistema nervoso central, é responsável pelo funcionamento harmônico da face durante a respiração, mastigação, sucção, deglutição e fala, em alguns casos não há uma adequada avaliação de um dano quando essas estruturas são lesadas 5 .

Embora se saiba que o dente é um órgão, pois é biologicamente definido como um conjunto de três tecidos (esmalte, dentina e polpa) trabalhando em conjunto para executar uma ou mais funções específicas (mastigatória, fonética e estética) ${ }^{3}$, o mercado segurador nacional ainda não confere direito à indenização por invalidez permanente por perda dental e danos estéticos, mesmo em casos comprovados de perda, redução ou impotência funcional definitiva, total ou parcial.

Nesse contexto, o presente trabalho tem como objetivo revisar a literatura odontológica relacionada às lesões traumáticas do sistema estomatognático à luz do Direito Securitário, discutindo a importância da avaliação das lesões dentais nas perícias de Invalidez Permanente por Acidente (IPA).

\section{Revisão de literatura}

\section{Funções dos dentes e consequências de suas perdas}

A perda de dente permanente por ação traumática ou patológica pode ocasionar alterações significativas nas funções mastigatória e fonética, além de comprometer a estética dentária durante o sorriso e a conversação.

A mastigação é, sem dúvida, a função mais importante do sistema estomatognático, sendo a fase inicial do processo digestivo, em que os dentes recebem papel de destaque, pois executam funções específicas. Na função mastigatória, os incisivos centrais e laterais têm o papel de cortar os alimentos, os caninos, o de rasgar, os pré-molares, o de triturar e os molares, o de amassar os alimentos ${ }^{6}$. Uma mastigação funcional está diretamente relacionada a uma adequada oclusão dental, uma cinética músculo-articular normal, uma abóbada palatina íntegra, uma língua de volume suficiente e uma função labial adequada?

A falta de dentes também altera a fala, prejudicando, consequentemente, a boa dicção, na medida em que muitos sons são produzidos mediante a ação da língua sobre eles ${ }^{8}$. Em relação à perda de dentes anteriores, a fonética fica prejudicada durante a pronúncia de palavras que envolvem principalmente fonemas classificados como linguodentais (palavras em que se pronunciam as letras " $\mathrm{t}$ " $\mathrm{e}$ "s") e labiodentais (palavras em que se pronuncia a letra "f").

Por último, o dano estético é um dano extrapatrimonial, podendo ser entendido como toda alteração da morfologia externa ou alteração funcional do lesionado, que se traduz em uma perda da beleza ou atração com respeito ao estado anterior da pessoa ${ }^{9}$.

\section{Legislação e função do perito securitário}

De acordo com Silva ${ }^{10}(2009)$, a Circular SUSEP 302/05 ${ }^{11}$ e a Resolução CNSP $117 / 04^{12}$ são normativas infralegais onde se encontram as regras de funcionamento e os critérios para operação das coberturas de risco oferecidas em plano de seguro de pessoas.

Uma das coberturas securitárias descritas na Circular SUSEP 302/05 é a de IPA, que pode ser observada nos Arts. 11 e 12 da referida norma:

Art. 11. A cobertura de invalidez permanente por acidente garante o pagamento de uma indenização relativa à perda, à redução ou à impotência funcional definitiva, total ou parcial, de um membro ou órgão por lesão física, causada por acidente pessoal coberto [...].

Art. 12. Após conclusão do tratamento, ou esgotados os recursos terapêuticos disponíveis para recuperação, e constatada e avaliada a invalidez permanente quando da alta médica definitiva, a sociedade seguradora deve pagar uma indenização, de acordo com os percentuais estabelecidos nas condições gerais e/ou especiais do seguro.

Entretanto, o $\$ 7^{\circ}$ do Art. 12 da Circular SUSEP 302/05 ${ }^{11}$ estabelece explicitamente: A perda de dentes e os danos estéticos não dão direito à indenização por invalidez permanente.

Em seguros de pessoas, a função do perito é a de avaliar o dano corporal previamente informado, considerando critérios contratuais. A primeira atribuição do perito é verificar se o evento alegado caracteriza um acidente pessoal e equivale a examinar se o evento descrito preenche os critérios concei- 
tuais acima descritos. Num segundo momento, cabe ao perito o estudo do nexo de causalidade entre o evento coberto e o dano corporal, e, estabelecendo-se a relação de causalidade entre o traumatismo e as lesões físicas decorrentes e as sequelas em análise, o perito deve quantificá-la em termos percentuais de acordo com as regras que constam na Circular SUSEP 302/05 $5^{10,11}$.

O conceito de acidente pessoal consta no Art. $5^{\circ}$ da Resolução CNSP 117/04 ${ }^{12}$, que o estabelece como sendo o evento com data caracterizada, exclusivo $e$ diretamente externo, súbito, involuntário, violento e causador de lesão física, que, por si só e independente de toda e qualquer outra causa, tenha como consequência direta a morte, ou a invalidez permanente, total ou parcial do segurado, ou que torne necessário tratamento médico.

\section{Metodologia da avaliação do dano corporal em seguros de pessoas}

De acordo com Silva ${ }^{10}$ (2009), a metodologia da avaliação do dano corporal em seguros de pessoas, de uma maneira geral, não se diferencia de outros campos do Direito. Varia quanto aos objetivos específicos da perícia e à redação de sua conclusão, considerando as particularidades contratuais.

Em comparação ao mercado segurador da Europa e dos Estados Unidos da América, o reconhecimento da necessidade de cobertura para danos pessoais mediante apólices de seguros é recente no Brasil, e as empresas que prestam esse tipo de serviço são, em sua maioria, multinacionais que adaptam os seus produtos originais às condições do país. A implementação dessa modalidade de seguro ampliou o mercado de trabalho dos cirurgiões-dentistas, que agora também podem atuar na avaliação de lesões que acometam o complexo maxilomandibular e de suas consequências, viabilizando ao segurado a obtenção do reembolso a que tem direito quando da ocorrência de danos dessa natureza. Esse tipo de avaliação compreende o nexo causal entre o trauma e o dano alegado, o tempo necessário para o restabelecimento, os tratamentos propostos e os honorários profissionais ${ }^{13}$.

\section{Metodologia da avaliação do dano bucomaxilofacial}

Pérez et al. ${ }^{7}$ (1996) relatam que o dano bucodental é pouco importante no contexto de outras lesões sensitivas e motoras, reflexo de sua função exercida dentro de um parâmetro geral do organismo humano. Nem por isso, entretanto, se pode descuidar do rigor de nossa exploração e valoração.

Bussac e Carbonnie ${ }^{14}$ (1997) observam que o dano dental pode aparecer no passado como um elemento secundário da reparação do dano corpo- ral. O dente, órgão menor, é considerado por esses autores como sendo fácil de substituir e não parecia haver problemas em decorrência de sua perda. A frequência de lesões traumáticas dentais isoladas ou associadas a outros traumatismos, a tomada de consciência do papel funcional e estético dos dentes, a aparição de técnicas de substituição cada vez mais sofisticadas e de custos elevados, no entanto, deram uma nova importância a uma avaliação que, em certos casos, pode se revelar fácil, mas, em outros, pode ser de grande complexidade.

\section{Avaliação do dano no Brasil e no exterior}

Sempre que a vítima tornar-se portadora de qualquer alteração definitiva da integridade psicofísica que lhe cause qualquer limitação de uma capacidade que tinha, ela apresentará uma incapacida$\mathrm{de}^{15}$. Habitualmente essa incapacidade, na maioria dos casos, é parcial, e sua definição é o índice médico-legal mais significativo para auxiliar a missão de quantificação de dano em termos de indenização ${ }^{16}$.

As tabelas de avaliação de taxa de incapacidade permanente são ferramentas de medida que permitem ao perito referenciar essas incapacidades parciais em pontos ou valores percentuais. Não substituem os peritos, já que não são um manual de patologia sequelar, nem uma metodologia de avaliação específica ${ }^{17}$.

O método de percentagem de incapacidade bem manejado constitui um excelente meio para quantificar a alteração da integridade psicofísica e calcular o total dos danos que devem ser reparados à vítima $^{18}$. As tabelas exercem um papel considerável na indenização de vítimas que sofreram um dano corporal, permitindo uma análise racional das funções com base em taxas de referências comuns, e as perdas dos diversos tipos de dentes são quantificadas nas tabelas internacionais ${ }^{19}$.

No Brasil, existem duas tabelas de indenização de incapacidades permanentes parciais, sendo uma estabelecida pela SUSEP ${ }^{11,20}$ e outra para obtenção do seguro decorrente de Danos Pessoais Causados por Veículos Automotores de Via Terrestre (DPVAT $)^{20}$, mas nenhuma delas faz referência à perda de dentes.

No que diz respeito às lesões dentais, estas são totalmente excluídas da cobertura de indenização pela legislação brasileira que regulamenta a cobertura de dano permanente a um órgão, como visto no $\S 7^{\circ}$ da Circular SUSEP 302/05 ${ }^{11}$.

Uma das maiores dificuldades na valoração das sequelas em acidentes pessoais é a falta de indicação, na apólice do seguro, de outra tabela - mais completa - que possa ser utilizada quando as lesões analisadas não estiverem contempladas. 
Da mesma maneira, as consequências nas funções mastigatória e fonética, as alterações na deglutição, no paladar, na motricidade e na sensibilidade crânio-mandibular e as disfunções têmporo-mandibulares, dentre outras, são valoradas independentemente das perdas dentais na União Europeia e não são consideradas nas coberturas de acidentes pessoais no Brasil ${ }^{21}$.

As lesões nos dentes, assim como os prejuízos estéticos e outros parâmetros de dano corporal (quantum doloris) que repercutem nas atividades desportivas e de lazer, têm, na França, uma cobertura securitária denominada de "acidentes da vida privada". Além da taxa de invalidez, em decorrência de prejuízos fisiológicos, são indenizáveis os prejuízos econômicos, ou seja, as perdas financeiras imputadas diretamente ao acidente e os chamados prejuízos particulares ou pessoais, dano estético e repercussão nas atividades desportivas e de lazer, cujos conceitos encontram-se descritos nos parâmetros de dano corporal medicamente valorizáveis ${ }^{10}$.

\section{Discussão}

O homem é um ser único e total, não podendo haver, portanto, dicotomia dos seus órgãos. Se algo não vai bem com ele, todo o organismo é prejudicado, o que comprova que não somos estanques, mas interligados holisticamente ${ }^{13}$.

A própria Odontologia, no decorrer dos anos, tem passado por diversas fases, mostrando que, muitas vezes, a desvalorização dos dentes e demais componentes do sistema bucomaxilofacial provém, em primeira instância, do próprio profissional da área, acarretando, assim, uma grande influência na população circundante.

O sistema estomatognático era visto como um sistema à parte, e os dentes, muitas vezes, percebidos pela população como artefatos descartáveis sem muita valia, quando comparados, separadamente, aos outros órgãos do organismo humano. Tal fato ocorria em razão da falta de conhecimento das suas funções e das consequências de uma perda ou lesão dental, aparentemente considerada simples, no contexto global do nosso organismo. Talvez devido a esse mesmo sistema cultural lentamente avançado é que os elementos dentais foram estigmatizados, em tempos mais remotos, como órgãos secundários e a lesões dentais foram vistas como de gravidade menor, dificultando, assim, sua valoração e tipificação.

A Circular SUSEP no $302 / 05^{11}$, no seu $§ 7^{\circ}$, descarta a perda do dente para indenização por invalidez permanente. Em que pese a exclusão de cobertura para perdas dentais e os danos estéticos na legislação securitária, vale lembrar o prejuízo funcional que, eventualmente, essas lesões determinam. Essa desvalorização do sistema estomatognático e, principalmente, do dente no âmbito securitário brasileiro é uma lacuna já esclarecida em outros países onde o dente é valorado como órgão anatômico e funcional.

A tabela da SUSEP ${ }^{11,20}$ somente quantifica a fratura de maxilar inferior não consolidada, referente às sequelas do sistema estomatognático, mostrando a necessidade de revisão na atual legislação securitária brasileira.

\section{Considerações finais}

O presente estudo, baseado na revisão da literatura e legislação vigente sobre a indenização de incapacidade permanente parcial por acidente, observa que a perda do dente em acidentes pessoais não é valorada, desconsiderando-se o dente como órgão do corpo humano.

Portanto, há necessidade de revisão da atual legislação securitária brasileira para que as perdas dentais sejam cobertas em casos de IPA, de modo semelhante a outros países que já adotaram tabelas específicas de avaliação de incapacidades que quantificam as perdas dentais.

\section{Abstract}

Objective: to show the importance of assessing dental injuries in the forensics of permanent disability by accident, through a literature review and analysis of specific legislation. Literature review: the stomatognathic system, when balanced and controlled by the central nervous system, is responsible for the harmonious functioning of the face during breathing, chewing, sucking, swallowing, and speaking. In this system, teeth have an imperative role in masticatory and phonetic functions, and although they are biologically considered as organs, accidental dental loss is not supported by the current insurance legislation (SUSEP 302/05, and CNSP Resolution 117/04). Final considerations: due to the lack of expertise in this area, there is a mismatch between the purpose of personal accident insurance and the repair of dental damages, especially in teeth, where it becomes important to disclose this information in dental and legal environment so that legal regulations may be changed and beneficiaries may fairly and lawfully enjoy their rights.

Keywords: Stomatognathic system. Insurance claim review. Legal dentistry.

\section{Referências}

1. Carvalho TBO, Cancian LRL, Marques CG, Piatto VB, Maniglia JV, Molina FD. Seis anos de atendimento em trauma facial: análise epidemiológica de 355 casos. Br J Otorhinolaryngol 2010; 76(5):565-74.

2. Figueiredo MC, Cesar MO, Silva JP, Borba EM. Prevalência de mulheres vítimas de violência no município de Porto Alegre e a influência de suas variáveis no âmbito odontológico. Rev Fac Odontol Univ Passo Fundo 2012; 17(3):254-60. 
3. Bath-Balogh M, Fehrenbach MJ. Anatomia, histologia e embriologia dos dentes e das estruturas orofaciais. 2. ed. Barueri: Manole; 2008.

4. Cardozo HF. Avaliação médico-legal das lesões do complexo maxilo-mandibular. In: Silva M. Compêndio de Odontologia Legal. Rio de Janeiro: Medsi; 1997. p. 289-317.

5. Doria MVRC. Das lesões corporais. Campinas: Servanda; 2009.

6. Silva M. Considerações sobre enquadramento das lesões dentárias no artigo 129 do Código Penal Brasileiro. In: Tochetto D. 2. ed. Identificação humana. Campinas: Millenium; 2003. p. 375-80.

7. Pérez BP, Garrido BR, Sánchez JAS. Metodología para la valoración del daño bucodental. Madrid: Editorial Mapfre; 1996.

8. Douglas CR. Tratado de fisiologia aplicado à saúde. 5. ed. Rio de Janeiro: Guanabara Koogan; 2002.

9. Criado del Río MT. Valoración médico-legal del daño a la persona. In: Tomo II. Doctrina médico-legal de valoración de daños personales. Madrid: Colex; 2010. p. 375-432.

10. Silva WFM. Perícia securitária. In: Epifhanio EB, Vilela JRPX. Perícias médicas: teoria e prática. Rio de Janeiro: Guanabara Koogan; 2009. p. 259-67.

11. Brasil.. Circular no 302 , de 19 de setembro de 2005. Brasília: Superintendência de Seguros Privados (SUSEP); 2005. Disponível em URL: http://www.susep.gov.br/textos/circ302. pdf.

12. Brasil. Resolução CNSP n⿳0 117, de 22 de dezembro de 2004. Brasília: Conselho Nacional de Seguros Privados (CNSP); 2004. Disponível em URL: http://www.susep.gov.br/menu/ textos/resol117-04.pdf.

13. Consentino SRC. Perícias de ressarcimento de danos em companhias seguradoras: análise da adequação dos tratamentos propostos, dos custos dos tratamentos e da documentação. [Dissertação de Mestrado]. São Paulo: Faculdade de Odontologia da USP; 2005.

14. Bussac M, Carbounie CL. Le dommage dentaire et son évaluation. Revue Française Dommage Corporel 1997; 23(4):437-54.

15. Vieira DN, Quintero JA. Aspectos práticos da avaliação do dano corporal em Direito Civil. Coimbra: Caixa Seguros; 2008.

16. Sá FO. Clínica médico-legal da reparação do dano corporal em Direito Civil. Coimbra: APADAC; 1992.

17. Bessières-Roques I, Fournier C, Hugues-Béjui H, Riche F. Précis d'évaluation du dommage corporel. 2. ed. Paris: L'argus de L'assurance; 2001.

18. Mélennec L. Valoración de las discapacidades y del daño corporal. Baremo Internacional de Invalideces. Madrid: Masson; 2000.

19. Lambert-Faivre $Y$, Porchy-Simon S. La détermination des préjudices de la victime directe. In: Lambert-Faivre Y, Porchy-Simon S. Droit du dommage corporel. Systèmes d'indemnisation. 7. ed. Paris: Dalloz; 2012. p. 142-207.

20. Brasil. Tabela para Cálculo da indenização em caso de invalidez permanente. Atualizada em 01. set. 2010. Brasília: Superintendência de Seguros Privados (SUSEP); 2010. Disponível em URL: http://www2.susep.gov.br/menuatendimento/seguro_pessoas_consumidor.asp\#ap.
21. Bouchardet FCH. Avaliação do dano bucomaxilofacial: metodologia europeia aplicada ao contexto brasileiro [Dissertação de Mestrado]. Coimbra: Universidade de Coimbra; 2006.

Endereço para correspondência:

Fernanda Capurucho Horta Bouchardet Avenida do Contorno, 4852/408,

Funcionários

30110-100 Belo Horizonte - MG

Fone : (31) 9312-5555

Email: fernandacapurucho@gmail.com

Recebido: 22 / 11 /2013. Aceito: 25 / 11 / 2013. 